\title{
Las tecnologías digitales y su impacto en la Universidad. Las nuevas mediaciones
}

\author{
Digital technologies and their impact on Higher \\ Education. The new mediations
}

\author{
Juan de Pablos Pons \\ Universidad de Sevilla (España)
}

\section{Resumen}

Este trabajo propone una reflexión sobre la evolución de los medios en la era digital, y la necesidad de avanzar en el conocimiento sobre los procesos de mediación y remediación, que propician las nuevas tecnologías, diferenciándolos de los generados hasta ahora por los medios analógicos tradicionales (libro impreso, cine, televisión). La digitalización ha dado lugar a nuevas realidades y propuestas, como las redes sociales, los videojuegos o las aplicaciones de realidad aumentada. El siguiente paso en nuestra cultura de medios está siendo la multiplicación y diversificación continuada de formatos, y por tanto de nuevas formas de interacción mediada. Los procesos de mediación generados contribuyen a la modificación de modelos de comunicación y también formas de enseñanza. Es evidente su impacto en las instituciones educativas, y en la universidad. Como contribución a este análisis se aporta y define el concepto de remediación tecnológica. Las nuevas tecnologías de la información y la comunicación (TIC) representan, bajo las consideraciones aquí formuladas, una oportunidad de cambio en algunos aspectos y procedimientos de los mandatos principales de la universidad: docencia, investigación y gestión. Ser proactivo ante esta nueva realidad es determinante, ya que la capacidad de adaptación está vinculada a la supervivencia de la propia universidad.

Palabras clave: universidad; tecnologías de la información y la comunicación (TIC); enseñanza virtual; mediación tecnológica; gestión de instituciones.

\begin{abstract}
This work proposes a reflection on the evolution of media in the digital age, requires us to advance in knowledge about mediation and remediation processes, favored by technologies, differentiating them from those generated so far by traditional analogue media (printed book, film, television). Digitization has given rise to new realities and proposals, such as video games, social networks or augmented reality applications. The next step in our media culture is the multiplication and continuous diversification of formats, but also new forms of mediated interaction. The mediation processes generated contribute to the modification of communication models and teaching methods. And this has an impact on educational institutions, and also on higher education. As a contribution to its analysis, the concept of technological remediation is provided and defined. The new information and communication technologies (ICT) represent, under the considerations formulated here, an opportunity for
\end{abstract}


change some forms and procedures of main areas of the higher education: teaching, research and management. Being proactive in this new reality is relevant, since the adaptation effort is linked to the survival of the university itself.

Keywords: higher education; Information and Communication Technologies (ICT); E-learning; technological mediation; institutional management.

La modernidad en la que se sitúan hoy nuestras sociedades avanzadas ha incorporado una serie de características que conviene tener presentes a la hora de analizar el impacto real producido por las nuevas tecnologías digitales en nuestra cultura. Este concepto, cultura, puede explicarse como el resultado de la gestión del pensamiento y el comportamiento humanos. Hablamos de un término cambiante que evoluciona y modifica sus referencias. La posmodernidad que viene a describir nuestro modo de vida en las sociedades actuales, y que se caracteriza por no mantener unos esquemas fijos que permitan analizar con sosiego la realidad, es calificada por Bauman (2017) como 'modernidad líquida'. Un concepto que lleva a considerar las situaciones y los procesos sociales en permanente transformación.

En coherencia con estos referentes cambiantes, una de las características más visibles de la cultura contemporánea es la presencia de las tecnologías en múltiples ámbitos y su constante evolución, muy acelerada en los últimos años. Uno de los aspectos más evidentes de esta realidad cultural es que nuestra relación con los medios se está transformando. La cultura mediática actual desde luego sigue incluyendo formatos tradicionales como libros en soporte papel, fotografía, cine, radio o televisión; aunque todos ellos tienen versiones digitales, a las que accedemos mediante múltiples soportes como e-books, tablets, ordenadores portátiles, smartphones, televisores digitales o relojes inteligentes. Estas tecnologías que hoy nos acompañan en muchas de las actividades que realizamos cotidianamente, se caracterizan por su ubicuidad. Y las nuevas aplicaciones digitales como las redes sociales, los videojuegos o la realidad aumentada, inciden en las formas de mediación que los medios generan. Esto influye en la manera en que nos relacionamos con la información y con los productos culturales.

Si nos situamos en el campo educativo, la proyección de la realidad antes descrita ha ido produciendo cambios e incorporaciones que han tenido un impacto y por tanto ha generado nuevas necesidades, que las políticas educativas han asumido y cuyas decisiones se han ido concretando en inversiones y cambios en los modelos de gestión. También ha habido cambios en las formas de enseñanza, incorporando nuevas infraestructuras, herramientas digitales y formas de trabajar. Si nos circunscribimos al ámbito universitario, cabe hacer varias consideraciones.

En un interesante texto colectivo, compilado por Matthew S. Pittinsky (2006) se proponía a los diferentes autores participantes en el mismo, la cuestión de si la incorporación de nuevas opciones tecnológicas a la educación superior como 
el e-learning, suponía un proceso de cambio radical o progresivo. Levine (2006) responde a esta cuestión identificando cinco factores que impulsan los cambios. En primer lugar, cabe hablar de una sociedad que ha pasado de tener una base industrial a priorizar la información como motor económico. Esto supone un reto dirigido directamente a las universidades. La formación es una necesidad social, económica y ética, que sustenta la información y el conocimiento, y que además debe continuar durante toda la vida. En segundo lugar, el perfil de los estudiantes universitarios ha ido cambiando. En la actualidad su franja de edad se ha ampliado, de manera que no solamente son los jóvenes los que demandan una formación universitaria de calidad. También se han ido incorporando otros aspectos como la internacionalización o la inmigración que varían el perfil de los estudiantes. Esto ha generado una competencia entre las universidades para captar nuevos alumnos e inversiones, dando pie a comparaciones como las que se plasman en los diferentes 'rankings', que dibujan una lucha por la excelencia. El tercer factor de impacto, según Levine, es que va a ser clave la manera en que las instituciones universitarias resuelvan la integración de las nuevas tecnologías digitales, ya que constituye el mayor factor de expansión del que hasta ahora han dispuesto. El cuarto factor a tener en cuenta es el creciente peso de las universidades privadas; esto representa una realidad a nivel global, y también lógicamente en el caso de España. Esta incorporación viene favorecida precisamente por, entre otros factores, el uso de las tecnologías de la información y la comunicación (TIC). El quinto componente de cambio, según Levine, hay que buscarlo en la convergencia entre las empresas dedicadas a la creación de contenidos y conocimiento (editoriales, grupos mediáticos, museos, etc.) y las universidades, utilizando cada vez en mayor medida las nuevas tecnologías para difundir sus productos. De hecho, hoy día la oferta de 'cursos' es muy amplia a todos los niveles, de manera que la formación superior, formal y no formal, no es exclusiva del mundo universitario.

Estas referencias siguen siendo vigentes hoy para un análisis actual de la realidad formativa en la universidad. Y parece lógico añadir un sexto factor a tener en cuenta, y es el tipo de exigencia dirigido a los estudiantes, ya que en un marco influido por el modelo implementado por el Espacio Europeo de Educación Superior, deben ser más proactivos, colaborativos y autosuficientes. Estas exigencias dirigidas a la universidad actual, piden respuestas eficientes. Autores como Joseph Stiglitz y Bruce Greenwald (2015) han planteado la necesidad de generar un cambio global hacia una "sociedad del aprendizaje", en la que todo gire alrededor de la creación y la gestión del conocimiento.

En el ámbito de la investigación, la universidad ha venido manteniendo un estatus preferente, ya que ha conseguido en buena medida preservar su capacidad en este campo, apoyándose en la libertad académica. Este derecho universitario se deriva del término lehrfreiheit, una práctica proveniente de la universidad alemana del siglo XIX, que hace referencia a la libertad del profesorado para llevar a cabo la investigación y enseñar los resultados de la misma en el aula y fuera de ella, sin 
interferencias institucionales o sociales (Levine, 2006, p. 35). Si bien, este aspecto también ha empezado a modificarse al tomar otras instancias iniciativas en este campo, como los gobiernos, estableciendo prioridades en sus convocatorias públicas de programas de investigación, o las empresas privadas que ven en la investigación un nicho de progreso y de negocio.

En la incorporación de las tecnologías digitales a la universidad influyen factores diversos como los señalados con anterioridad, pero en último término, para que la enseñanza y el aprendizaje evolucionen hacia nuevas formas, buscando la mejora, es el profesorado la pieza clave y el que marca el camino a seguir. Es su concepción docente la que debe servir de referencia, pero para buscar esa mejora debe tener un apoyo institucional, que a su vez debe saber ordenar sus prioridades.

\section{LAS TECNOLOGÍAS DIGITALES EN LA UNIVERSIDAD}

Las instituciones universitarias están obligadas a afrontar retos importantes, de manera que las soluciones que adopten en estos tiempos cambiantes, marcarán su futuro. Estas exigencias pasan por reformular algunos planteamientos o tradiciones que han marcado la personalidad de estas instituciones a lo largo del tiempo. Así, en relación a ellas, se viene hablando de 'inteligencia institucional', entendida como la "capacidad de la universidad para dar a cada miembro de la comunidad universitaria acceso autónomo a toda aquella información analítica de valor para el óptimo desempeño de sus funciones, a través de canales especializados y permanentes, obteniendo una utilización eficaz de los mismos" (Alcolea Picazo y Pavón de Paula, 2013). Estos planteamientos suponen un cambio de mentalidad en la gestión de las universidades y en las actitudes de sus gestores y de su profesorado, en clave más participativa en la toma de decisiones individuales y colectivas.

En cuanto al papel de las tecnologías digitales, debemos partir de la referencia que Internet y las TIC no se idearon pensando en la mejora de los procesos educativos. Su finalidad más global afecta a las dinámicas sociales y económicas en general. Los creadores de redes sociales como Mark Zuckerberg (Facebook), Jack Dorsey (Twitter), o Jimmy Wales al proponer repositorios colaborativos de información como Wikipedia, no pensaron que sus invenciones podrían llegar a tener un uso específicamente educativo. Sin embargo, estas herramientas tienen un gran potencial en ese campo. De ahí la importancia de la adaptación de las mismas a los contextos educativos; adaptación que debe realizarse tanto desde la perspectiva del estudiante como del profesorado y los gestores. Así ocurre con los campus virtuales. En su inicio eran plataformas pensadas para apoyar la gestión de los servicios académicos y la comunicación entre estudiantes y profesores. Posteriormente se han ido adaptando a las necesidades de la enseñanza y del aprendizaje (Dias, Diniz y Hadjileontiadis, 2014). La investigación en este ámbito también es fundamental para valorar la eficacia de estas adaptaciones tecnológicas y desarrollar aplicaciones concretas para los diferentes contextos educativos. 
Existe un error extendido en el mundo educativo, consistente en considerar las nuevas tecnologías únicamente como sustitutivas de tecnologías precedentes, impidiendo así la innovación y el cambio en los procesos de enseñanza-aprendizaje. Tal como señalan Duart y Reparaz (2011) el principal cambio que comporta el uso de la tecnología en el proceso docente está en el énfasis que se debe poner en la definición de los objetivos de aprendizaje de los estudiantes, más que en los tradicionales contenidos, lo que supone hacer más flexibles las propuestas metodológicas encaminadas al aprendizaje. Por tanto, la tecnología es un recurso al servicio de la planificación del aprendizaje. Hoy en día conocemos contextos definidos a partir del uso de las tecnologías como la semi-presencialidad, o blended learning, los contextos híbridos, o los no presenciales o en línea. Entendemos por híbridos aquellos que van más allá de los semipresenciales, los cuales se limitan a definir dos espacios paralelos: presencialidad/no presencialidad. El contexto híbrido permite la elaboración de un 'continuo educativo' (Osorio, 2010) que permite al estudiante estar en continuo proceso de aprendizaje, independientemente de la modalidad en la que se encuentre. De la misma forma que permite a los docentes estar permanentemente influyendo en el proceso docente con independencia de la modalidad presencial o no presencial.

En el ámbito universitario, tanto en el caso de instituciones que imparten formación presencial, como las que lo hacen a distancia, se ha generalizado el uso de los denominados campus virtuales (García Aretio, Ruiz Corbella y Domínguez Figaredo, 2007). Se trata de plataformas tecnológicas que permiten la gestión de un determinado formato de aprendizaje, a la vez que posibilita la comunicación entre los miembros del grupo-clase y el acceso a la información considerada relevante. La configuración que el profesorado aporte a estas plataformas tecnológicas, puede condicionar su uso docente. Las concepciones y creencias de los profesores sobre los usos docentes de las tecnologías influyen directamente en el diseño de su planificación. En un estudio específico se han expuesto algunas conclusiones sobre la enseñanza apoyada en el uso de plataformas virtuales en entornos virtuales universitarios. Los resultados obtenidos permiten establecer como conclusiones relevantes que las prácticas de enseñanza en línea, están mediadas por las concepciones y creencias pedagógicas del profesorado; pero a su vez los usos tecnológicos influyen y transforman dichas concepciones (De Pablos, Colás y González, 2011).

El modelo virtual puede constituirse, y en este sentido se ha insistido quizás de manera interesada, en una fórmula útil para reducir costos y llegar a un número mayor de personas. Pero, en realidad, se trata más bien de optimizar nuevas posibilidades comunicativas y formativas. La atención más personalizada al estudiante, implementando tutorías, reduciendo en parte las clases magistrales en la enseñanza universitaria, y en definitiva incorporando otros procedimientos de acceso a la información. Todas estas son alternativas viables. En cuanto a los costos, no se trata tanto de abaratar los procesos de formación superior, sino de mejorar significativamente los procesos formativos. De hecho, no es real ese abaratamiento, a no ser que rebajemos la calidad de la formación (De Pablos, 2010). 


\section{LA MEDIACIÓN TECNOLÓGICA}

La mediación, entendida como modalidades de interacción, propiciada por las tecnologías es un constructo clave para comprender los procesos de aprendizaje. Se ha abordado desde diferentes teorías, incluso desde campos de conocimiento diferenciados (filosofía, sociología, psicología). Nosotros, vamos a aproximarnos a este concepto, apoyados en los presupuestos teóricos del enfoque histórico-cultural, algunos de cuyos fundamentos han sido aportados por investigadores como Vygotsky (2014), Leontiev (1978) y Luria (1980). El psicólogo norteamericano Michael Cole actualizó el concepto de mediación, propiciada por herramientas cognitivas. Formuló el concepto de artefacto que puede ser definido como "un aspecto del mundo material que se ha modificado durante la historia de su incorporación a la acción humana dirigida a metas" (Cole, 1999, p. 114). Según este planteamiento, la doble acepción del concepto representa una capacidad transformadora, tanto desde el punto de vista mental como físico, por parte del usuario de artefactos. En el primer caso, estaríamos ante una actividad intelectual, y en el segundo frente a una actividad de tipo material. El artefacto, en último término, persigue una mediación funcional, tanto desde el punto de vista material como personal. La diferenciación entre ambas viene dada por el tipo de interacciones y de respuestas generadas entre realidad y sujeto.

El punto de partida lo constituye la cultura, que incorpora todas aquellas claves que nos permiten agregarnos a un grupo social con unas determinadas características y que utiliza un conjunto de instrumentos culturales muy precisos y determinados; en muchas ocasiones promovidos por las instituciones. Los componentes de intermediación entre esas referencias externas (cultura) y el individuo serían los niveles interpsicológico e intrapsicológico, que son conceptos vygotskianos, y que se vinculan precisamente a esos procesos dependientes entre sí que identificamos respectivamente como procesos psicológicos básicos y procesos psicológicos superiores. El nivel interpsicológico nos da el soporte para esas capacidades básicas que apoyan lo que luego vamos a denominar inteligencia o procesos psicológicos superiores. De tal manera que en ese nivel interpsicológico se llevan a cabo una serie de procesos, siendo el primero el que permite conocer y dominar todas esas pautas socioculturales. El recorrido termina o culmina con la internalización, que vendría a ser la reelaboración personal de todos esos elementos externos. Entre ambas se identifican una serie de pasos intermedios. Los procesos de apropiación suponen una primera fase vinculada al manejo de instrumentos; la apropiación suele generar resistencias y tensiones que exigen una adaptación. La privilegiación, permite optar por determinadas posibilidades de lo que me he apropiado; de todo lo que aprendo no utilizo todo, sólo determinadas cosas en función de circunstancias, contextos o situaciones. El siguiente paso, la reintegración ya está bajo el paraguas del nivel intrapsicológico. Aquí, se inicia un proceso por el cual la persona aplica de forma autónoma lo aprendido a nuevas situaciones diferenciadas, acudiendo a 
nuevos contextos para probar lo que anteriormente consta que ha funcionado en una situación concreta y que ha sido aprendido con apoyo externo.

Para poder transitar por los diferentes niveles, es fundamental la acción mediada. Yesa acción mediada sólo es posible concretarla a través delos instrumentos culturales como el lenguaje oral y escrito, tal como argumentó Vygotsky, pero también otros lenguajes y tecnologías como los lenguajes audiovisuales, los lenguajes informáticos o la narrativa virtual. Se trata de un recorrido que además es permanente, ocurre durante toda la vida, no es un proceso que, como hacen determinadas teorías evolutivas, señala un escalón final, un determinado estadio que culmina un proceso. Pero no es sólo un recorrido de lo externo a lo interno, de lo social a lo individual. El carácter necesariamente dinámico que está en la base de esta concepción toma forma a través de otro proceso más, que denominamos exteriorización, que hace referencia a la producción o aportación del sujeto hacia el ámbito colectivo a partir de sus propias elaboraciones, lo que facilita la actividad en colaboración (Daniels, 2003).

Los procesos de mediación proporcionan un vínculo crucial entre los contextos históricos, culturales e institucionales y el desarrollo de un tipo de pensamiento más abstracto y complejo. Las consideraciones teóricas aquí formuladas en torno a un modelo que trata de representar la acción mediada abren el camino para profundizar en el estudio de los instrumentos y, por tanto, en comprender mejor los procesos de la construcción de la identidad cultural de los sujetos.

\section{El concepto de remediación}

La actualización del concepto de mediación está vinculado a la aparición de nuevas tecnologías que modifican nuestra percepción de la realidad y su representación. En un momento clave como es el cambio de siglo, David Bolter y Richard Grusin (1999) desarrollan el concepto de remediación, para explicar la manera en que los medios se influyen entre sí, haciendo referencia por ejemplo al 'diálogo' obligatorio entre los medios digitales (Internet o videojuegos) y los medios tradicionales (cine y televisión). Previamente Bolter (1996) empieza a desarrollar el término remediación, a partir de los contenidos analizados por Rheingold (1991) sobre la realidad virtual. Bolter y Grusin (2011) reivindican en la teoría de la remediación el valor y aplicación de la tecnología en un entorno comunicativo que se adapta a los nuevos medios, modificando así el propio contexto social. La remediación no se vincula a un único medio, sino que se desarrolla en una sinergia y conjunción de varios factores sociales que interaccionan a través de los diferentes medios tecnológicos. Los creadores y productores de nuevas formas digitales se han apoyado en modelos y estilos ya utilizados para la generación de nuevos contenidos. Así, las versiones en línea de los periódicos, han copiado la estructura de sus versiones en papel, pero aportan inmediatez en la actualización de las noticias, o las empresas venden sus productos desde sus páginas web, agilizando los procesos comerciales. Estos cambios se 
han universalizado con gran rapidez. De hecho, los procesos de remediación han continuado su avance, en función de la aparición de nuevas tecnologías y soportes. Así, un medio convencional será parte, de alguna manera, del nuevo medio; por tanto, cada novedad mediática incorporará algo de la tecnología que está sustituyendo.

La remediación es parte constituyente de cada nuevo medio, y las principales características que la definen son la inmediatez, que hoy es elemento definitorio de la comunicación social mediada por la Red, y la hipermediación, entendida como una sobreabundancia de informaciones y recursos que se manifiestan en realidades virtuales o en entornos cotidianos. Así, la interfaz gráfica ha reemplazado a la interfaz de mandos en el teclado, que era completamente textual. Al introducir objetos gráficos en el esquema de representación, los diseñadores creyeron que estaban haciendo más "transparentes" las interfaces, y por tanto, más "naturales" (Bolter y Grusin, 2011, p. 39).

En la obra 'La comprensión de los medios', Marshall McLuhan señalaba que el "contenido" de cualquier medio es a su vez otro medio distinto. Así, el contenido de la escritura es una representación del lenguaje oral (McLuhan, 2009). La representación de un medio en otro es lo que denominamos remediación, que es una característica definitoria de los nuevos medios digitales. De hecho, en la actualidad la televisión e Internet pugnan por determinar qué medio dominará los mercados mediáticos en los próximos años. Como la televisión, el cine también intenta absorber y reposicionarse con la tecnología digital. Los efectos especiales y las películas de animación están siendo absorbidos por las imágenes digitales.

El concepto de remediación es útil al considerar las consecuencias de la introducción de un nuevo medio, en el contexto mediático actual (Bolter y Engberg, 2016). Estos autores explican la remediación, en términos de un proceso que consiste en "aislar elementos de medios tradicionales y reconfigurarlos de maneras nuevas" (p. 151). Las configuraciones resultantes potencian los aspectos positivos de las propuestas iniciales y resuelven problemas o debilidades pendientes. Esta perspectiva da pie a considerar que la incorporación de los nuevos medios o tecnologías, en clave de cultura de medios, no representan una revolución o ruptura respecto a los medios precedentes, sino más bien suponen un proceso de adaptación, que en muchos casos tiene un carácter colectivo o cooperativo. En todo caso, una de las características de las formas actuales de la tecnología y sus próximos desarrollos será la multiplicación y diversificación de formatos, que convivirán entre sí. Y esto es así, porque los medios digitales más dominantes, frente al objetivo de universalización que buscaban los medios tradicionales en el siglo pasado (radio, cine, televisión), aportan un grado de individualización o personalización para colectivos específicos que precisan propuestas adaptadas para ámbitos concretos como el trabajo, el ocio, el comercio o la educación.

El proceso de remediación opera en ambas direcciones: los usuarios de los medios tradicionales como el cine y la televisión pueden buscar apropiarse de las imágenes de ordenador, igual que los artistas digitales pueden remodelar el cine y 
la televisión con nuevas soluciones. Un video digital es una remediación del cine, a la vez que éste lo es del teatro. Este contexto de remediación constante que se da en la tecnología digital, no sólo es una forma útil de avanzar en el progreso, sino que es una condición necesaria para que podamos interactuar con los nuevos medios. De hecho, cabe hablar de procesos de hibridación. Algunas de las aplicaciones de realidad aumentada, donde a través de la pantalla de una tablet o un teléfono inteligente aumentamos la realidad física, jugamos sobre el plano físico hibridando con la información que nos muestra el display de la aplicación. Por tanto, la hibridación de los medios radica en la relación que se produce entre los diferentes componentes que los forman; en las técnicas de software que los hacen posibles y, en fin, en cómo transmiten la experiencia al usuario, mediante una suma independiente de componentes, $\mathrm{o}$ a través de una propuesta integrada.

\section{EL FUTURO DE LA UNIVERSIDAD VINCULADO A LAS TIC}

En la modernidad líquida a la que nos hemos referido, las universidades se ven abocadas a enfrentar nuevos retos que están provocando cambios en sus modelos de funcionamiento. Uno de los más importantes es su necesaria adaptación a los nuevos sistemas de comunicación con los estudiantes. La presencia de los docentes en redes sociales, blogs y otros entornos colaborativos está empezando a ser habitual. La comunicación con el alumnado tiende a ser menos presencial, y está dando pasos hacia modelos que contemplan la virtualización de la enseñanza. Paulatinamente se dejará de hablar de presencialidad y no presencialidad para pasar a hablar de interacción alumno-docente en un sentido más amplio. Consecuentemente, los elementos que aporta la remediación como la inmediatez y la hipermediación, deben ser tenidos en cuenta para mejorar los procesos de comunicación, la creación de materiales formativos o la implementación de modelos de gestión.

La faceta investigadora, componente que ha venido siendo clave en la concepción de las universidades en Europa, también está siendo afectada por esta nueva realidad. Como remarca la Asociación de Universidades Europeas (EUA):

El vínculo entre educación superior e investigación es básico en la educación superior europea y en la definición del carácter de las universidades en Europa. Los gobiernos necesitan ser conscientes de dicha interacción y promover vínculos más estrechos entre los Espacios Europeos de Enseñanza Superior y de Investigación para así robustecer la capacidad de investigación en Europa y mejorar la calidad y capacidad de atracción de la educación superior europea. (Bricall, 2004, p. 29).

La investigación en todos los ámbitos del saber tiende a ser más distribuida y colaborativa. En este sentido, las digitalización de las tecnologías está teniendo ya un papel esencial en la agregación del conocimiento a nivel mundial y en la potenciación de las actividades investigadoras de las universidades. El futuro de la investigación 
se apoya cada vez más en redes de gestión del conocimiento, donde la cooperación internacional abierta y flexible de grupos de investigación pertenecientes a distintas universidades y empresas, tiende a una gestión más eficiente de la $\mathrm{I}+\mathrm{D}+\mathrm{i}$, y para la obtención de resultados. Estos enfoques están generando nuevas realidades como la necesidad de disponer de un acceso estructurado a gigantescas cantidades de información y de estándares para su gestión.

Como se apunta en informes como el de la Fundación Telefónica: 'Universidad 2020: Papel de las TIC en el nuevo entorno socioeconómico' (2011), en las actividades investigadoras se hará cada vez más uso de tecnologías de realidad virtual, que permitirán la recreación de los experimentos incluso fuera del entorno del laboratorio físico. Estas tecnologías de realidad virtual serán ampliamente utilizadas en los procesos de investigación en materias como medicina, biología, física, química, robótica, etc. Del mismo modo, las grandes y costosas infraestructuras de investigación serán compartidas entre diferentes grupos de investigación en todo el mundo.

Uno de los aspectos de la investigación que también quedará afectado, respecto a la situación actual en los próximos años será el de la publicación de resultados. La progresiva generalización de las herramientas sociales como blogs, wikis o páginas web personales para publicar (o pre-publicar) por parte de los grupos de investigación de sus avances en los proyectos de investigación, abrirá nuevas posibilidades frente a la realidad actual. Esta "socialización" de los resultados de investigación, que estarán disponibles fuera de los ámbitos académicos habituales, contribuirá a romper el actual statu quo configurado por las revistas científicas. Esta tendencia debe ser positiva tanto en lo referente a la difusión del conocimiento como a su divulgación, haciéndolo más asequible a la sociedad.

El pasado mes de octubre se han celebrado en Madrid las Jornadas de la Sectorial de Tecnologías de la Información y las Comunicaciones (TIC) de la Conferencia de Rectores de las Universidades Españolas (CRUE), bajo la temática "Estrategias TI para la Universidad del Futuro". En sus conclusiones se recoge que son muchos los retos que la universidad española afronta, en la ya planteada transformación digital, en la que todas las universidades, en mayor o menor medida, están inmersas. Las TIC se han ido convirtiendo en un componente estratégico. Y aspectos como la implantación de la administración electrónica es en estos momentos una prioridad.

\section{A MODO DE CONCLUSIÓN}

Los procesos de mediación generados por las tecnologías tradicionales, como el libro, el cine o la televisión, y la remediación creada por las nuevas tecnologías digitales, como las redes sociales, la realidad aumentada o los videojuegos, tal como se ha formulado en este artículo, plantean una cuestión clave para conocer el papel real que juegan los medios en la transmisión de la información y su contribución a la generación de conocimiento. La comprensión de la remediación es la llave que 
permite entender las características de los medios digitales actuales. Hay autores que hacen referencia al concepto de reciclaje para identificar el desarrollo inicial de un nuevo medio; algo que quedará atrás cuando este encuentre su propia estética y función. En realidad se trata de un proceso dialéctico entre medios anteriores y actuales, que alimenta los avances tecnológicos. Es un paso hacia una nueva concepción de los medios que realmente es mucho más radical y revolucionaria que la simple cohabitación de diferentes tipos de medios.

Hemos hablado aquí de la hibridación de los medios como una modalidad específica de remediación. Se trata de un concepto relevante, que debe entenderse como un proceso que "amenaza" la constitución de cada uno de los elementos por separado, el texto no se entiende igual desde que lo podemos manipular digitalmente, lo mismo ocurre con las imágenes y el vídeo, la convivencia entre el vídeo (editado), las imágenes (modificadas) y el texto superpuesto, genera un entorno experiencial totalmente diferente. Estas nuevas mediaciones que hemos identificado como remediaciones, apoyadas en procesos de hibridación, contienen un gran potencial en el ámbito educativo, ya que permiten abordar con mayor facilidad que las tecnologías convencionales los procesos de interacción, que están en la base del aprendizaje.

Las nuevas tecnologías digitales representan, bajo las consideraciones aquí formuladas, una oportunidad de cambio y mejora en las formas y procedimientos de interacción social y de acceso a la información. Los nuevos componentes presentes en la interactividad comunicativa, explicados aquí en clave de procesos de mediación renovados (remediación/hibridación), que propician las nuevas tecnologías, aportan soportes para una «transformación de la cultura docente». En cuanto a la investigación, también está siendo afectada por las tecnologías tanto en aspectos de procedimiento, como en su difusión, tal como aquí también se ha señalado. Y la gestión, buscando un salto cualitativo en la mejora de su eficacia, por ejemplo mediante la implantación de la administración electrónica, es una cuestión ya en vías de ser generalizada en las universidades españolas, según hemos recogido, a partir de recientes iniciativas de la CRUE.

Para entender convenientemente este complejo proceso de cambio, es relevante valorar la manera en que los integrantes de la comunidad universitaria perciben la transformación que su institución está viviendo en el siglo XXI.

\section{NOTAS}

1. http://tic.crue.org/jornadas-crue-tic-estrategias-ti-para-la-universidad-del-futuro/

\section{REFERENCIAS BIBLIOGRÁFICAS}

Alcolea Picazo, J., y Pavón de Paula, S. (2013). Los datos como recurso estratégico Libro Blanco sobre Inteligencia Institucional en Universidades. Madrid: OCU (Oficina de Cooperación Universitaria), 17-43. 
Bauman, Z. (2017). Vida líquida. Barcelona: Austral/Paidós.

Bolter, D. (1996). Virtual Reality and Redefinition of Self. En L. Strate, R. Jakobson y S.B. Gibson (Eds.) Communication and Cyberspace: Social Interaction in an Electronic Environment (105-120). New York: Hampton Press.

Bolter, D., y Grusin, R. (1999). Remediation: Understanding New Media, Cambridge, Massachusetts: The MIT Press.

Bolter, D., y Grusin, R. (2011). Inmediatez, hipermediación, remediación. CIC. Cuadernos de Información $y$ Comunicación, 16. Recuperado de http://www.redalyc.org/articulo. oa?id=93521629003

Bolter, J., y Engberg, M. (2016). Entornos aumentados y nuevos medios digitales. En Varios (2016): El próximo paso. La vida exponencial. Edición BBVA, Madrid, 140-158.

Bricall, J. M. (2004). La Universidad ante el siglo XXI. En A. Sangrá y M. González Sanmamed (Coord.): La transformación de las universidades: a través de las TIC: discursos y prácticas (19-29). Barcelona: Editorial UOC.

Cole, M. (1999). Psicología cultural. Madrid: Morata.

Daniels, H. (2003). Vygotsky y la Pedagogía. Barcelona: Paidós.

De Pablos, J. (2009). El marco del impacto de las Tecnologías de la Información.

Herramientasconceptualesparainterpretarla mediación tecnológica educativa. Revista Telos. Cuadernos de Comunicación, Tecnología y Sociedad, 67. Recuperado de https://telos.fundaciontelefonica. com/telos/articulocuaderno.asp@ idarticulo $=3 \&$ rev $=67 . \mathrm{htm}$

De Pablos, J. (2010). Universidad y sociedad del conocimiento. Las competencias informacionales y digitales. En Varios: Competencias informacionales y digitales en educación superior [monográfico en línea]. Revista de Universidad y Sociedad del Conocimiento (RUSC), 7(2). UOC. Recuperado de http://rusc.uoc.edu/ojs index.php/rusc/article/view/v7n2-depablos/v7n2-de-pablos

De Pablos, J., Colás. M. P., y González, T. (2011). La enseñanza universitaria apoyada en plataformas virtuales. Cambios en las prácticas docentes: el caso de la Universidad de Sevilla. Revista Estudios sobre Educación, Núm. 20, 2348.

Días, S.B., Diniz, J. A. y L. J. Hadjileontiadis (2014). Towards an Intelligent Learning Management System Under Blended Learning. New York: Springer.

Duart, J. M., y Reparaz, Ch. (2011). Enseñar y aprender con las TIC. Estudios sobre educación, 20, 9-19.

Fundación Telefónica (2011). Universidad 2020: Papel de las TIC en el nuevo entorno socioeconómico. Madrid: Fundación Telefónica/Ariel.

García Aretio, L. (Coord.), Ruiz Corbella, M. y Domínguez Figaredo, D. (2007). De la educación a distancia a la educación virtual. Barcelona: Ariel.

Gil Serra, A., y Roca-Piera, J. (2011). Movilidad virtual, reto del aprendizaje de la educación superior en la Europa 2020. Revista de Educación a Distancia (RED), 26. Recuperado de http://www.um.es $\mathrm{ead} / \mathrm{red} / 26$

Leontiev, A. N. (1981). Activity, conciousness, and personality. Englewood, Clifs: Prentice Hall.

Levine, A. (2006). Educación superior: una revolución externa, una evolución interna. En M. S. Pittinsky (Comp.), $L a$ Universidad conectada (25-42). Málaga: Ediciones Aljibe.

Luria, A. R. (1980). Los procesos cognitivos. Análisis sociohistórico. Barcelona: Fontanella.

McLuhan, M. (2009). La comprensión de los medios como las extensiones del hombre, Barcelona: Paidós Ibérica. 
Osorio, L. A. (2010). Características de los ambientes híbridos de aprendizaje: estudio de caso de un programa de posgrado de la Universidad de los Andes. Revista de Universidad y Sociedad del Conocimiento (RUSC), 7(1), 1-9. Recuperado de http://rusc.uoc.edu/rusc/ es/index.php/rusc/article/view/v7n1 osorio.htm
Pittinsky, M. S. (Comp.) (2006). La Universidad conectada. Málaga: Ediciones Aljibe.

Rheingold, H. (1991). Virtual Reality. New York: Simon and Shuster.

Varios (2016). El próximo paso. La vida exponencial. Madrid: Edición BBVA.

Vygotsky, L. S. (2014). Obras escogidas II: Pensamiento y lenguaje. Conferencias sobre psicología. Madrid: Editorial Antonio Machado.

\section{PERFIL ACADÉMICO Y PROFESIONAL DEL AUTOR}

Juan de Pablos Pons. Catedrático de Universidad en el Departamento de Didáctica y Organización Educativa de la Universidad de Sevilla (España). Director del Grupo de Investigación Evaluación y Tecnología Educativa, vinculado al Plan Andaluz de Investigación. Evaluador de proyectos I+D de distintas agencias nacionales y autonómicas. Las líneas de investigación preferentes, desarrolladas durante los últimos años han sido: Las TIC aplicadas a la educación; las políticas educativas y la integración de las TIC; la formación del profesorado; y el desarrollo del Espacio Europeo de Educación Superior. Actualmente es miembro de la Comisión Académica del Programa de Doctorado en Educación de la Facultad de Ciencias de la Educación de la Universidad de Sevilla. Es Presidente de la Red Universitaria de Tecnología Educativa (RUTE), desde el año 2012.

E-mail: jpablos@us.es

\section{DIRECCIÓN DEL AUTOR}

Facultad de Ciencias de la Educación.

Universidad de Sevilla

C/ Pirotécnia, s/n. 41013 Sevilla (España)

Fecha de recepción del artículo: 20/12/2017

Fecha de aceptación del artículo: 11/01/2018

\section{Como citar este artículo:}

Pablos Pons, J. d. (2018). Las tecnologías digitales y su impacto en la Universidad. Las nuevas mediaciones. RIED. Revista Iberoamericana de Educación a Distancia, 21(2), pp. 83-95. doi: http://dx.doi.org/10.5944/ried.21.2.20733 